\title{
Analysis of Entropy Generation Rate During Non-Adiabatic Ice Slurry Flow in Pipes
}

\author{
Niezgoda-Żelasko Beata * \\ Institute of Thermal and Process Engineering, Cracow University of Technology \\ al. Jana Pawła II 37, 31-864 Kraków, Poland \\ E-mail: bniezgo@mech.pk.edu.pl
}

Received 15 January 2020, Revised 14 February 2020, Accepted 14 February 2020

\begin{abstract}
The paper focuses on the entropy generation rate minimization during the flow of ethanol-based ice slurry through straight pipes with a circular and rectangular cross-section. The authors' original equations for calculating ice slurry flow resistances and heat transfer coefficients were used to determine the impact of the mass fraction of ice, ice slurry flow velocity and heat flux density on the entropy generation rate values observed during flow through pipes. A dimensionless relationship was proposed to determine the interdependency between flow velocity and mass share of ice for which the entropy values were at the minimum level. The parameter areas in which the entropy flux was minimal were related for different cross-sections of the transverse flow to the areas of parameters $x_{s}$ and $w$ in which the values of overall enhancement efficiency were higher than one. Thus, a method for verifying the parameters of slurry velocity and mass fraction selected in the design process according to two different criteria was proposed.
\end{abstract}

Keywords: ice slurry, entropy generation rate, melting process, tube flow, slit channel

\section{Introduction}

The regulation of the European Parliament and the Council of Europe from 2014 and executive decisions of the EU Commission regarding fluorinated greenhouse gases significantly reduce the use of HFC and FC coolants even in the next two years. These limitations present new challenges for the design of large refrigeration and air conditioning systems. In addition, striving to reduce the greenhouse effect is related to the need to improve the energy efficiency of refrigeration and air-conditioning systems, which, even in moderate climate conditions, constitute a high power load for the operated industrial or construction facilities. One solution to minimise the amount of coolant in the installation and reduce energy consumption is to use indirect cooling systems with cold storage systems. Due to its properties, ice slurry meets the expectations of modern heat carriers in this respect. The ice slurry is a mixture of water ice crystals $\left(d_{s}=10^{-4}-0.5 \mathrm{~mm}\right)$ and water with the addition of a freezing point lowering agent. The mass fraction of ice in the dispersion that can be pumped does not exceed $x_{s} \leq 30 \%$. The presence of particulate matter in the mixture determines a number of properties which are unusual for coolants. The possibility of using latent ice melting heat significantly reduces the coolant mass flux and storage tank capacity, as well as the required maximum efficiency of chillers - ice slurry generators [1]. The phenomena accompanying the flow and exchange of heat with the application of ice slurry were the subject of detailed research presented in studies by Doetsch [2] Egolf at al. [3], Niezgoda-Żelasko and Żelasko [4], Illán and Viedma [5], Mellari [6]. Ice slurries belong to the group of non-Newtonian fluids, which generally have higher flow resistance than single-phase coolants [7]. However, in terms of homogeneous flow, the presence of ice crystals taking over part of the kinetic energy of turbulence from the carrier fluid results in creating velocity ranges for which the slurry flow resistance may be lower than the flow resistance for the carrier fluid [8]. The micro convection effect caused by the presence of solid particles [9], [10] and the high thermal capacity of the slurry, improve the heat transfer coefficients in the laminar flow range in comparison to single-phase coolants as 2...5.7 times [11]. However, in the turbulent flow range, an increase of $20-30 \%$ in heat transfer coefficients in relation to the carrier fluid is observed [11]. Therefore, in the process of designing systems powered by ice slurry, the values of heat transfer coefficients should be maximised, while maintaining the lowest possible values of flow resistance. An important design issue in the case of slurries is providing for a homogeneous flow of the mixture. Figure 1 shows the boundary curves $w\left(X_{V m}\right)$ for the different flow structures formed by the ethanol ice slurry during flow in pipes $\left(d_{i}=0.01,0.02 \mathrm{~m}\right)$ [12].

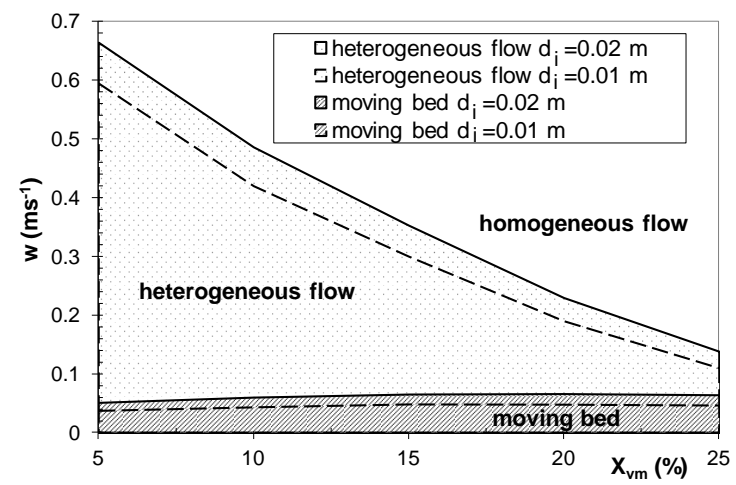

Figure 1. Flow structures of ethanol ice slurry, flow in tube $d_{i}=0.01 \mathrm{~m}$ and $d_{i}=0.02 \mathrm{~m}$

Without a doubt, ice particles intensify the heat exchange process, allowing to reduce the surface area of heat 
exchangers supplied with ice slurry, while the latent heat of ice melting and large ice mass fractions allowing to reduce the mass flux of the coolant. The efficiency of using ice slurry as a coolant can be determined on the basis of criteria commonly used in heat exchange. An obvious assessment indicator for the effectiveness of various methods of improving heat exchange conditions is the so-called overall enhancement efficiency defined as $\varepsilon_{\mathrm{Nu}-f}=\left(\mathrm{Nu} / \mathrm{Nu}_{\mathrm{ref}}\right) /\left(f / f_{\mathrm{ref}}\right)^{1 / 3}$ [13].

The second principle of thermodynamics and the concept of entropy flux are also used for thermodynamic evaluation of processes involving ice slurry [14]. In works [15] and [16], Bejan number and irreversibility distribution ratio was used to assess the intensification of the heat exchange process in rectangular duct with packed spherical particles [15] and in annular packed bed [16]. The values of these numbers allow to determine thermodynamically optimal flow parameters and construction parameters of devices with minimum lost of available energy.

There is little literature available regarding the application of the second principle of thermodynamics to the design of ice slurry systems. Paper [17] compared waterbased slurries with PCM and MCNT (multi-walled carbon nanotubes) elements. The results presented by them prefer the use of PCM elements in cases of small pipe diameters and low density of heat fluxes. Thermal processes taking place in the laminar flow range as well as at larger pipe diameters and heat flux densities display preference to the use of MCNT elements. In the turbulent flow range, the lowest entropy flux values were generated for water as a heat carrier. Bouzid at al. [18] presented an analysis of the entropy flux during isothermal, laminar flow of ice slurry being an Ostwald-de Waele fluid. In addition to the thermal and flow phenomena on the coolant and cooling medium side, Strub at al. [19] analysed the balance of the entropy flux in a heat exchanger supplied with ethanol ice slurry, indicating the advisability of using ice slurries with low mass fraction of ice. A more comprehensive approach to the application of the second principle of thermodynamics in the design of heat exchangers with ice slurry was presented by Kaymar at al. [20]. The study by Kaymar at al. [20] refers to the generation of an entropy flux during the non-adiabatic flow of ice slurry in a spiral heat exchanger. The authors showed the possibility of determining the value of Dean numbers for which the entropy flux was minimal.

The parameters describing the ice slurry used in the heat exchanger are the mass fraction of ice and mass flux, which determine the momentum and heat exchange and generate different values of the entropy flux. The paper presents and compares the ranges of the mass fractions of ice and flow velocities for which the entropy fluxes reached minimum values in case of the ethanol ice slurry, as a Bingham fluid, during non-adiabatic flow through the slit channel $(0.003 \times 0.0358 \mathrm{~m})$ and straight pipes $\left(d_{i}=0.01-0.02 \mathrm{~m}\right)$. For this purpose, custom criterion relationships were used to calculate the pressure drops and heat transfer coefficients for the ice slurry. The paper proposes a criterion relationship determining the relation between the mass fraction of ice and the velocity and density of the heat flux, for which the entropy flux was minimal. The parameter areas in which the entropy flux was minimal were related for different crosssections of the transverse flow to the areas of parameters $x_{s}$ and $w$ in which the values of overall enhancement efficiency were higher than one. Thus, a method for verifying the parameters of slurry velocity and mass fraction selected in the design process according to two different criteria was proposed.

\section{Determination of the Entropy Flux during Flow in Straight, Prismatic Channels}

\subsection{Flow with Phase Separation, Generation of Entropy in the Process of Ice Slurry Melting}

The first and second principles of thermodynamics expressed for the $\mathrm{d} l$ ice slurry control section (Fig. 2) are described by Eqs. (2.1) and (2.2), respectively.

$$
\mathrm{d} i_{I S}=T_{I S} \mathrm{~d} s_{I S}+v_{I S} \mathrm{~d} p_{I S}
$$

Figure 2. Heat exchange process in ice slurry during flow in a straight channel - schematic representation

The change in the entropy of ice slurry in the control section is described by Eq. (2.3):

$\dot{m}_{I S} \mathrm{~d} s_{I S}=\mathrm{d}\left(\dot{m}_{S} s_{S}+\dot{m}_{F} s_{F}\right)$

Equation (2.2) can be converted to the form of (2.4):

$\mathrm{d} \dot{S}_{l}=\frac{\mathrm{d} \dot{Q}}{\mathrm{~d} l}\left(\frac{1}{T_{w}}-\frac{1}{T_{I S}}\right)+\frac{\dot{m}_{I S}}{T_{I S}} \mathrm{v}_{I S}\left(-\frac{\mathrm{d} p_{I S}}{\mathrm{~d} l}\right)$

The definition of heat flux density $\mathrm{d} \dot{Q}=\dot{q} \mathrm{~d} A=\dot{q} P \mathrm{~d} l$ and Fourier Eq. (2.5) enable the conversion of Eqs. (2.4) to the form of (2.6):

$$
\begin{aligned}
& \Delta T=T_{w}-T_{I S}=\frac{\dot{q}}{\alpha_{I S}} \\
& \mathrm{~d} \dot{S}_{l}=\frac{\dot{q}^{2} P}{\alpha_{I S} T_{I S}^{2}+\dot{q} T_{I S}}+\frac{\dot{m}_{I S}}{T_{I S}} v_{I S}\left(-\frac{\mathrm{d} p_{I S}}{\mathrm{~d} l}\right)=\mathrm{d} \dot{S}_{l-H}+\mathrm{d} \dot{S}_{l-\Delta p}
\end{aligned}
$$

Equation (2.6) defines the entropy flux related to the unit length of the channel. The validity of the Eq. (2.6) depends on the assumption of a constant value of melting point for the ice slurry. It should be noted that the complete melting of a $30 \%$ ice slurry of a $10.6 \%$ ethanol solution in water is accompanied by a temperature glide of $2.2 \mathrm{~K}$. Therefore, in Eq. (2.6), temperature $T_{I S}$ is the mean temperature of the slurry $T_{I S}=\bar{T}_{I S}$.

\subsection{Ice Slurry Flow and Heat Exchange in Straight Channels}

The determination of the entropy generation rate from Eq. (2.6) for non-adiabatic flow of ethanol-based ice slurry requires the identification of both the pressure drop and the heat transfer coefficients for specific heat transfer conditions. The ice slurry under consideration is a Bingham fluid [8] and its flow can be treated as a generalized flow of a non-Newtonian fluid. By introducing the generalized form of the Reynolds number:

$$
\operatorname{Re}_{K}=\frac{\rho_{I S} w^{2-n^{*}} d_{h}^{n^{*}}}{8^{n^{*}-1} K^{*}}
$$




\begin{tabular}{|c|c|c|}
\hline Properties & Formula & Comments \\
\hline Enthalpy of ice slurry & $i_{I S}=\left(x_{s} / 100\right) i_{s}+\left(1-x_{s} / 100\right) i_{a}$ & \\
\hline Enthalpy of carrier liquid [21], [22] & $i_{a}=\Delta i_{m i x}+c_{p a}(T-273.15)$ & $\begin{array}{l}T_{r e f}=273.15 \mathrm{~K} \\
h_{a}=h_{a}\left(x_{a}, T\right)\end{array}$ \\
\hline Enthalpy of ice & $i_{s}=-r+c_{p s}(T-273.15)$ & $\begin{array}{l}r=332.4 \mathrm{~kJ} \mathrm{~kg}^{-1}[21], \\
{[22]}\end{array}$ \\
\hline Mean specific heat of ice slurry & $c_{p I S}=\left(x_{s} / 100\right) c_{p s}+\left(1-x_{s} / 100\right) c_{p a}$ & \\
\hline $\begin{array}{l}\text { Heat conductivity of ice slurry } \\
\lambda_{I S, w=0}[9]\end{array}$ & $\lambda_{\mathrm{IS}, \mathrm{w}=0}=\lambda_{\mathrm{a}} \cdot\left[\frac{2 \cdot \lambda_{\mathrm{a}}+\lambda_{\mathrm{s}}-2 \cdot\left(\beta_{\mathrm{s}} / 100\right)\left(\lambda_{\mathrm{a}}-\lambda_{\mathrm{s}}\right)}{2 \cdot \lambda_{\mathrm{a}}+\lambda_{\mathrm{s}}+\left(\beta_{\mathrm{s}} / 100\right)\left(\lambda_{\mathrm{a}}-\lambda_{\mathrm{s}}\right)}\right]$ & \\
\hline Ice slurry density & $\rho_{I S}=\left(X_{\mathrm{V}} / 100\right) \rho_{s}+\left(1-X_{\mathrm{V}} / 100\right) \rho_{a}$ & \\
\hline $\begin{array}{l}\text { Yield shear stress of ice slurry for } \\
x_{a i}=10.6 \% ; d_{s}=0.1-0.15 \mathrm{~mm}[12]\end{array}$ & $\begin{array}{l}\tau_{p}=0.013-1.4284\left(x_{s} / 100\right)+73.453\left(x_{s} / 100\right)^{2} \\
-394.64\left(x_{s} / 100\right)^{3}+835.82\left(x_{s} / 100\right)^{4}\end{array}$ & \\
\hline $\begin{array}{l}\text { Plastic viscosity of ice slurry for } \\
x_{a i}=10.6 \% ; d_{s}=0.1-0.15 \mathrm{~mm}[12]\end{array}$ & $\begin{array}{l}\mu_{p}=0.0035+0.0644\left(x_{s} / 100\right)-0.7394\left(x_{s} / 100\right)^{2} \\
+5.6963\left(x_{s} / 100\right)^{3}-19.759\left(x_{s} / 100\right)^{4}+26.732\left(x_{s} / 100\right)^{5}\end{array}$ & \\
\hline Parameter $K^{*}[9]$ & $\begin{array}{l}K^{*}=\left(c \mu_{p}\right)^{n^{*}} \tau_{w}^{1+d n^{*} / c} \\
{\left[\frac{c}{c+d} \tau_{w}^{1+d / c}-\frac{c}{d} \tau_{w}^{d / c} \tau_{p}+\frac{c^{2}}{d(c+d)} \tau_{p}^{1+d / c}\right]^{-n^{*}}}\end{array}$ & \\
\hline Parameter $n^{*}$ [9] & $n^{*}=\frac{c\left[\frac{1-\varepsilon_{B}^{1+d / c}}{c+d}-\frac{\varepsilon_{B}\left(1-\varepsilon_{B}^{d / c}\right)}{d}\right]}{1-\varepsilon_{B}-d\left[\frac{1-\varepsilon_{B}^{1+d / c}}{c+d}-\frac{\varepsilon_{B}\left(1-\varepsilon_{B}^{d / c}\right)}{d}\right]}$ & $\begin{array}{l}\varepsilon_{B}=\tau_{\mathrm{p}} / \tau_{\mathrm{w}} \\
c, d[24]\end{array}$ \\
\hline$X_{v}$ & $X_{v}=\left(1+\frac{1-x_{s}}{x_{s}} \frac{\rho_{s}}{\rho_{a}}\right)$ & \\
\hline
\end{tabular}

Fanning's factors for technically plain pipes can be found for the laminar and turbulent flow area on the basis of Eqs. (2.82.9):

$c_{f}=\frac{16}{\operatorname{Re}_{K}}$,

$c_{f}=\frac{0.079}{\operatorname{Re}_{K}^{0.25}}$.

$\Delta p=c_{f} \frac{2 l \rho_{I S} w^{2}}{d_{h}}$.

Equation (2.7) makes it necessary to determine a characteristic flow-behaviour index $n^{*}$ and consistency index $K^{*}$. For Bingham fluid and an arbitrary geometry of crosssection, these parameters are found from equations included in table 1 [8], [12].

For the generalized non-adiabatic flow of ice slurry, the heat transfer coefficient may be calculated for laminar and flow areas from Eqs. (2.11) and (2.12) [11], respectively:
$\mathrm{Nu}_{\mathrm{L}}=C_{1}\left(\mathrm{Gz}_{K}\right)^{C_{2}}\left(\frac{\Delta x_{s} \cdot \mathrm{K}_{F}}{100}\right)^{C_{3}}\left(\frac{d_{s}}{d_{h}}\right)^{C_{4}}\left(\frac{K^{*}\left(T_{I S}\right)}{K^{*}\left(T_{w}\right)}\right)^{C_{5}}$,

$\mathrm{Nu}_{\mathrm{T}}=C_{1}\left(\mathrm{Pe}_{K}\right)^{C_{2}}\left(\frac{d_{s}}{d_{h}}\right)^{C_{4}}$

The constants $B_{i}$ in Eqs. (2.11-2.12) are shown in Table 2 [11].

Hanks's criterion [9], was applied for changing the nature of motion, (Eqs. 2.13-2.15) true for Bingham fluid.

$\operatorname{Re}_{B C}=\left\{\begin{array}{cc}2100 \frac{1-4 / 3 \varepsilon_{B C}+1 / 3 \varepsilon_{B C}^{4}}{\left(1-\varepsilon_{B C}\right)^{3}} & \text { for tube } \\ \frac{1}{8} \sqrt{\frac{2}{3}}\left(\frac{1-3 / 2 \cdot \varepsilon_{B C}+1 / 2 \cdot \varepsilon_{B C}^{3}}{\varepsilon_{B C}}\right) H e^{*} & \text { for slit channel }\end{array}\right.$

where 


$$
\frac{\varepsilon_{B C}}{\left(1-\varepsilon_{B C}\right)^{3}}=\frac{\mathrm{He}^{*}}{A_{H e}}
$$

The constant in Eq. (2.14) is $A_{\mathrm{He}}=15000$ or $A_{\mathrm{He}}=22400$ respectively for flow through tubes or flow through a slit channel. In the case of flow through a tube, the constant in Eq. (2.14) was modified from the original Hanks relationship on the basis of own experimental studies from 16800 to 15000 [12]. The Hedström number $\mathrm{He}^{*}$ is defined for the characteristic dimension $d^{*}$ as defined by Eq. (2.15):

$$
d^{*}=\left\{\begin{array}{lr}
d_{i} & \text { for tube } \\
2 a \sqrt{\frac{2}{3}} & \text { for slit channel }
\end{array}\right.
$$

Table 2. Equations Values of coefficients in Eqs. (2.11) and (2.12).

\begin{tabular}{ccccc}
\hline $\begin{array}{c}\text { Cross } \\
\text { section }\end{array}$ & $\begin{array}{c}\text { Flow } \\
\text { type }\end{array}$ & $C_{i}$ & Value & $\begin{array}{c}\text { Applicability } \\
\text { range }\end{array}$ \\
\hline & & $C_{1}$ & 3.66 & \\
& & $C_{2}$ & 0.16 & $5.6 \%<x_{s}<30 \%$ \\
Slit & $\mathrm{L}$ & $C_{3}$ & -0.28 & $w_{m}>0.5 \mathrm{~ms}^{-1}$ \\
cross- & & $C_{4}$ & $-0,12$ & $30<\mathrm{Re}_{K}<2300$ \\
section & & $C_{5}$ & 0.16 & \\
\cline { 2 - 5 } & & $C_{1}$ & 0.0032 & $3 \%<x_{s}<30 \%$ \\
& $\mathrm{~T}$ & $C_{2}$ & 0.86 & $w_{m}<3.1 \mathrm{~ms}^{-1}$ \\
& & $C_{4}$ & - & $1900<\operatorname{Re}_{K}<6000$ \\
\hline & & $C_{1}$ & 2.52 & \\
& & $C_{2}$ & 0.11 & $3 \%<x_{s}<30 \%$ \\
& $\mathrm{~L}$ & $C_{3}$ & -0.10 & $w_{m}>0.1 \mathrm{~ms}^{-1}$ \\
Pipe & & $C_{4}$ & -0.35 & $200<\operatorname{Re}_{K}<2100$ \\
& & $C_{5}$ & 0.052 & \\
\cline { 2 - 5 } & & $C_{1}$ & 0.0096 & $3 \%<x_{s}<30 \%$ \\
& $\mathrm{~T}$ & $C_{2}$ & 0.70 & $w_{m}<4.5 \mathrm{~ms}^{-1}$ \\
& & $C_{4}$ & -0.10 & $2100<\operatorname{Re}_{K}<1100$ \\
\hline
\end{tabular}

\section{Analysis of the Entropy Flux for Ice Slurry in Straight \\ Channels}

The entropy generation rate was studied for a $10.6 \%$ ethanol solution-based ice slurry with a mass share of ice of $0<x_{s}<30 \%$. Calculations were made for ice slurry flow through straight tubes with diameters $d_{i}=0.01,0.016,0.02 \mathrm{~m}$ and slit channel $a \times b=0.003 \times 0.0358 \mathrm{~m}$ for heat flux density $2 \leq \dot{q} \leq 10 \mathrm{kWm}^{-2}$. Figure 3 presents the change in the total entropy generation rate as a function of the flow velocity and the mass fraction of ice during ice slurry flow through a $d_{i}=0.01 \mathrm{~m}$ pipe and for the flow through the slit channel under constant density conditions of the heat flux.

Figure 3 shows that regardless of the cross section of the channel, the lowest values of the entropy flux correspond to the low ice mass fractions $x_{s}<10 \%$. In the case of flow through tubes in the laminar flow area, the lowest generated entropy fluxes correspond to the maximum ice content in the slurry. In the entire flow range, the minimum value of the entropy flux is achieved in the turbulent flow range. These effects are related to the mutual relationship between the entropy fluxes generated by thermal and flow processes (Figure 4). In the case of a slit channel, high flow resistances determine the value of entropy flux already in the laminar flow area (Figure 5).

It should be noted, however, that in practical applications, e.g. in shell and tube heat exchangers, flow velocities of $w<1 \mathrm{~ms}^{-1}$ are used, whereas in plate heat exchangers $w<0.5 \mathrm{~ms}^{-1}$. In these velocity ranges however, the minimum entropy fluxes are obtained for the highest applied mass fractions of ice $x_{s}=30 \%$.
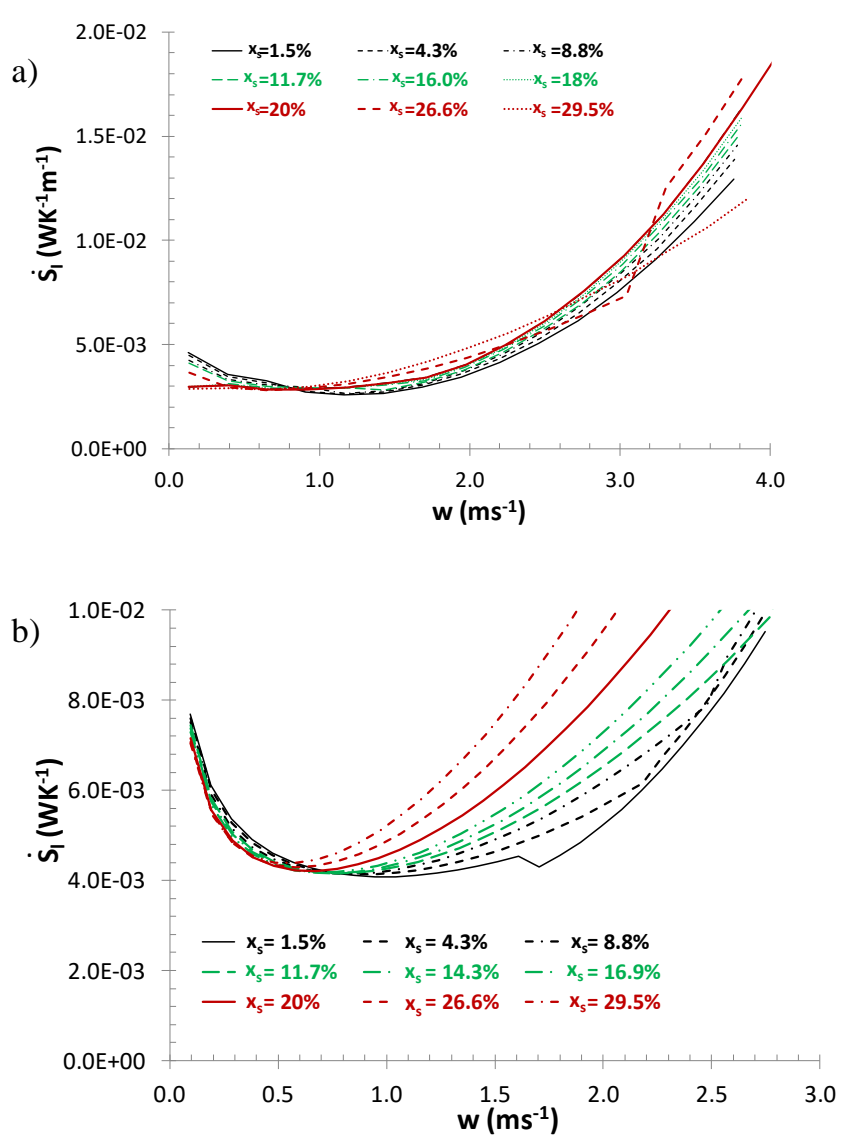

Figure 3. Total entropy generation rate as a function of the mass fraction of ice and ice slurry flow velocity: a) $d_{i}=0.01 \mathrm{~m}, \quad \dot{q} \cong 5 \mathrm{kWm}^{-2} \quad$ b) slit channel $a x b=$ $0.003 \times 0.0358 \mathrm{~m}, \dot{q} \cong 5 \mathrm{kWm}^{-2}$.

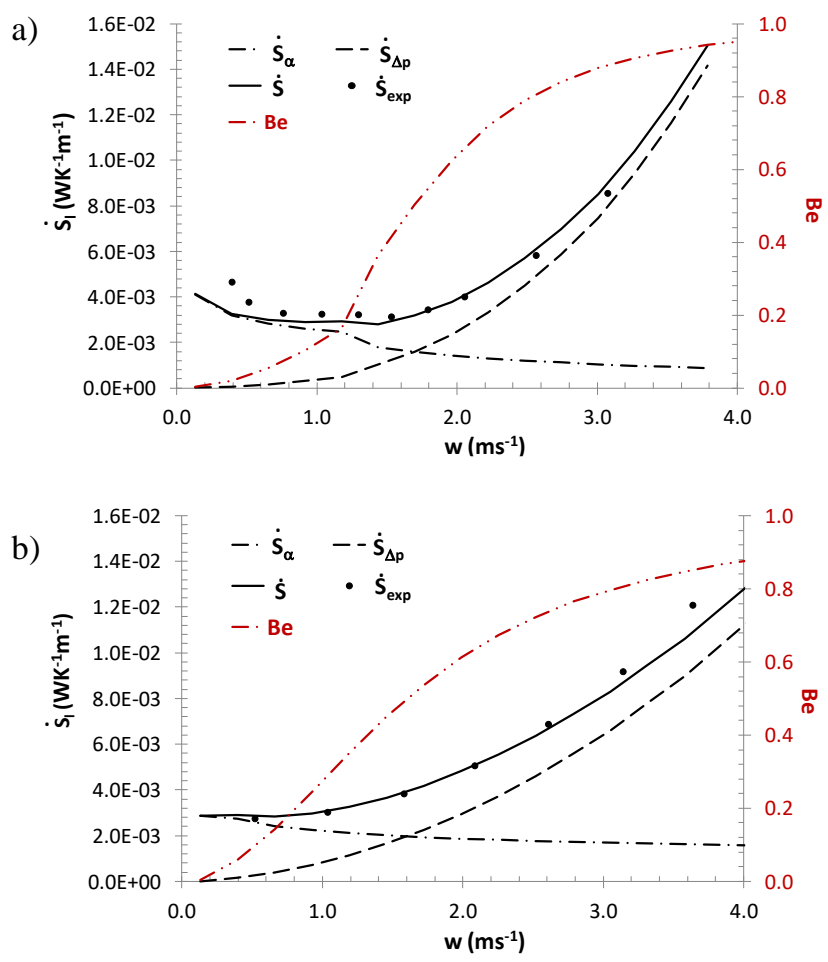

Figure 4. Relationship between entropy fluxes $\dot{S}_{H}, \dot{S}_{\Delta p}, \dot{S}$, and Bejan number for $d_{i}=0.01 \mathrm{~m}, \dot{q} \cong 5 \mathrm{kWm}^{-2}$ :

a) $x_{s}=11.7 \%$; b) $x_{s}=29.5 \%$. 
a)

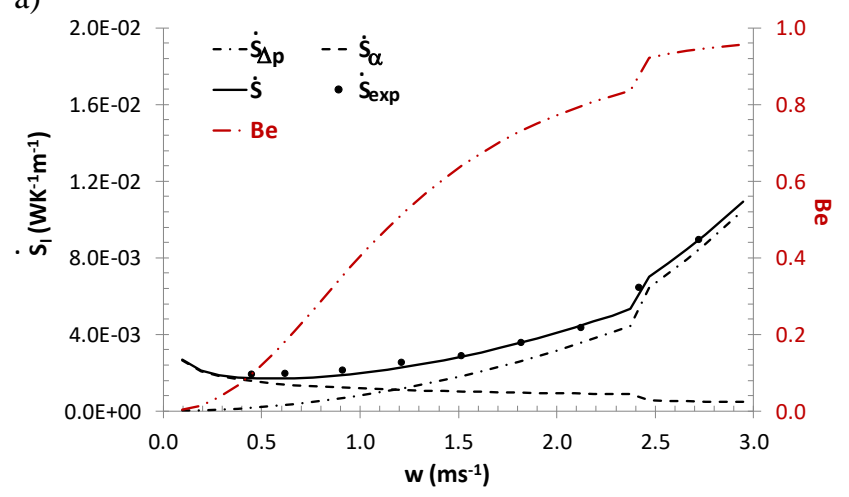

b)

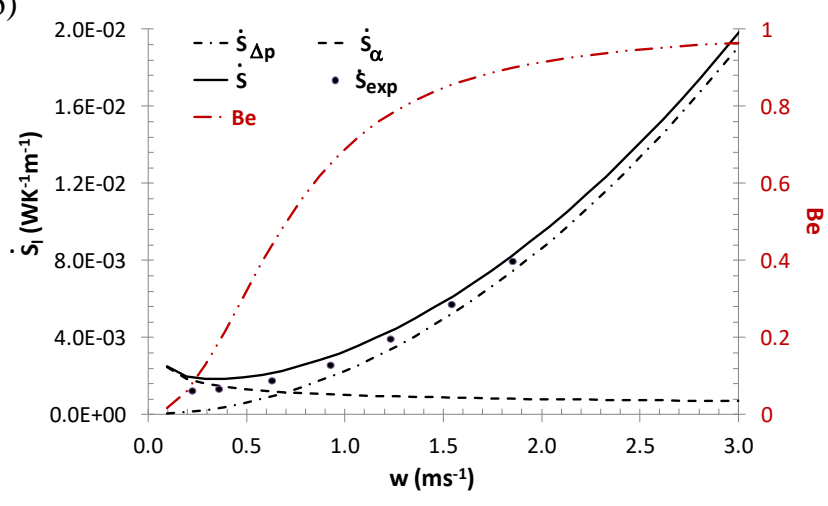

Figure 5. Relationship between entropy fluxes $\dot{S}_{H}, \dot{S}_{\Delta p}, \dot{S}$ and Bejan number, slit channel, $\left.\left.\dot{q} \cong 5 \mathrm{kWm}^{-2}: a\right) x_{s}=4.3 \% ; b\right)$ $x_{s}=29.5 \%$

a)

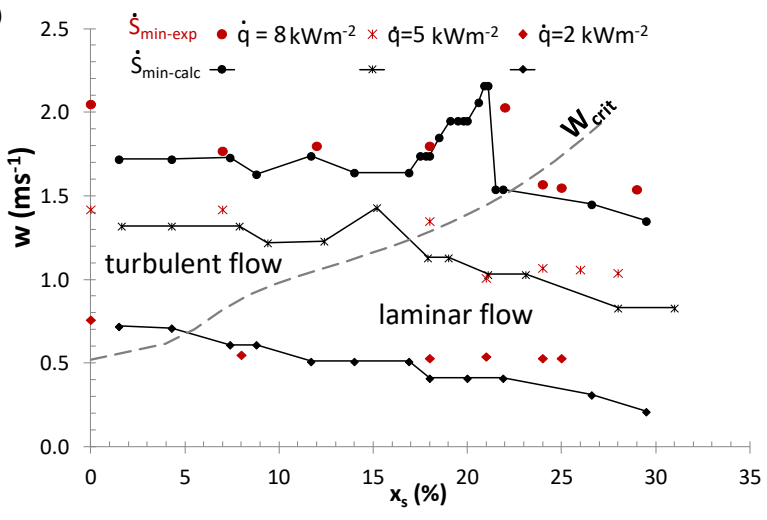

b)

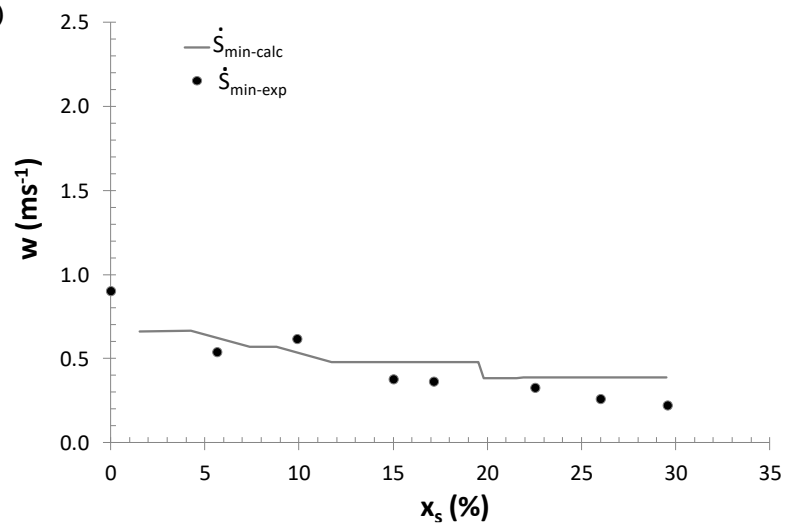

Figure 6. Parameters $w, x_{s}$ for which the entropy flux is minimal, as calculated and determined experimentally: a) $d_{i}=0.016 \mathrm{~m}, 2 \mathrm{kWm}^{-2} \leq \dot{q} \leq 8 \mathrm{kWm}^{-2}$, b) slit channel $\dot{q} \cong 5 \mathrm{kWm}^{-2}$.

Table 3. Values of coefficients in Eqs. (3.2) and (3.3)

\begin{tabular}{ccc}
\hline \multirow{2}{*}{ Parameter } & Tube & Slit channel \\
\cline { 2 - 3 }$D_{1}$ & $D_{1}=D_{11}\left(d_{i} / d_{0}\right)^{2}+D_{12}\left(d_{i} / d_{0}\right)+D_{13} ;$ & -1167.7404 \\
& $D_{11}=-2292.0231, D_{12}=10483.068, D_{13}=-4879.7335$ & \\
\hline \multicolumn{2}{c}{$D_{2}=D_{21}\left(d_{i} / d_{0}\right)^{2}+D_{22}\left(d_{i} / d_{0}\right)+D_{33} ;$} \\
$D_{2}$ & $D_{21}=-0.0708, D_{22}=0.2925, D_{23}=0.6583$ & 1.0498127 \\
\hline \multicolumn{3}{c}{11.3766} \\
\hline$D_{3}$ & 1.15317 & 7.27606 \\
\hline$D_{4}$ & 52.0511 & -1167.7404 \\
\hline$D_{5}$ & 10000 & \\
\hline$\dot{q}_{o}$ & 380 & \\
\hline$\dot{G}_{o}$ & 0.01 & \\
\hline$d_{i o}$ &
\end{tabular}

Figures 4 and 5 also show the entropy fluxes $\left(S_{\exp }\right)$ determined from Eq. (2.6) and the values of heat transfer coefficients and flow resistances determined experimentally [11]. Figures 4 and 5 also show the changes in Bejan numbers along with the change in ice slurry flow speed. Regardless of the cross-section of the flow, Bejan numbers corresponding to the minimum entropy flux values belonged to the range $0.14-0.36$.

Calculations made for different heat flux densities and tube diameters enabled the determination of mass flow velocities for which the total entropy flux reached a minimum value. Figure 6a shows the relationship $w\left(x_{s}\right)_{S \min }$ for the flow of ice slurry through a tube with a diameter of $d_{i}=0.016 \mathrm{~m}$ and different densities of heat fluxes. The analytically determined values of $w, x_{s}$ were verified experimentally.

The experimental values of $w, x_{s}$ were determined by calculating the value of entropy flux in each measurement point (Eq. 2.6) using the measured values of heat transfer coefficients and flow resistance [11]. Then, for the given values of $x_{s}$, measurement points were selected at which $\dot{S}=\dot{S}_{\min }$. Non-monotonic course of the relationship $w\left(x_{s}\right)_{\operatorname{smin}}$ for flow through tubes, is related to the transition area between the laminar and turbulent flows. This is illustrated in Figure 6a by marking the critical values of $x_{s}$ and $w_{C}$ determined from the Hanks criterion (formulas 2.13- 
2.15). A similar calculation was made for the flow through a slit channel. The results of calculations presented in Figure $6 \mathrm{~b}$ are limited to the density of the heat flux for which experimental studies have been carried out $\left(\dot{q} \cong 5 \mathrm{kWm}^{-2}\right)$. Good qualitative and quantitative consistency in the analytical and experimental determination of the entropy flux should be noted. The determined set of parameters $\left\{w, x_{s}\right\}$ for which $\dot{S}=\dot{S}_{\min }$ allowed to determine the correlation of the form Eq. (3.1) to determine the optimal parameters $w, x_{s}$ in different conditions of heat exchange with ice slurry.

$\operatorname{Re}_{I S-S_{\text {min }}}=K_{q}+K_{q X}$,

where

$$
\begin{aligned}
& K_{q}=D_{1}\left(\frac{\dot{q}_{o}-\dot{q}}{\dot{q}_{o}}\right)^{D_{2}}, \\
& K_{q X}=\exp \left(D_{3}+D_{4} \ln \left(\frac{d_{i}}{d_{i o}}\right)+D_{5} \frac{\dot{q}}{r \dot{G}_{o}}\left(\frac{X_{v}}{100}\right)\right) .
\end{aligned}
$$

Reynolds number $\operatorname{Re}_{I S \text {-Smin }}$ refers to the hydraulic diameter. The parameters $D_{i}, d_{i o}, \dot{q}_{o}, \dot{G}_{o}$ are listed in Table 3. Equation (3.1) enables the determination of the optimal velocity values for the condition $\dot{S}=\dot{S}_{\text {min }}$, for the assumed mass fractions, density of heat fluxes and cross sections of the flow with the maximum relative error of $15 \%$ (mean error 1.2\%) (Figure 7).
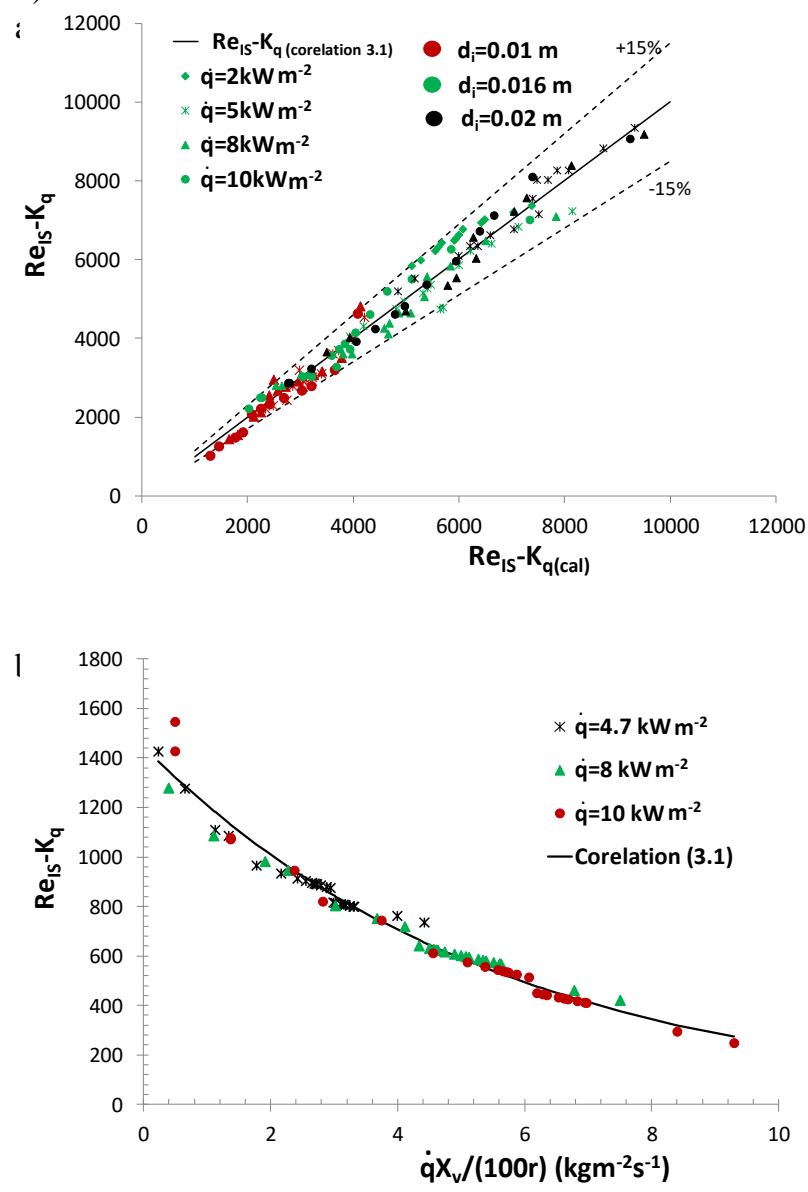

Figure 7. Comparison of the values calculated from Eq. (3.1) with the determined parameters of $\operatorname{Re}_{I S}$ and $\dot{q} X_{V} / r$ for which $\dot{S}=\dot{S}_{\min }$ : a) flow through tubes b) flow through a slit channel.
The minimum entropy flux criterion is not the only criterion for the evaluation of thermal and flow processes. As already mentioned, the evaluation of the thermal process intensification methods also uses e.g. the overall enhancement efficiency $\varepsilon_{\mathrm{Nu}-f}=\left(\mathrm{Nu} / \mathrm{Nu}_{\mathrm{ref}}\right) /\left(f / f_{\mathrm{ref}}\right)^{1 / 3}$. In the context of ice slurry application, it is interesting to compare the areas $\left\{w, x_{s}\right\}$ for which $\dot{S}=\dot{S}_{\min }$ or $\varepsilon_{\mathrm{Nu}-f}>1$. In Figure 8, a comparison of the limit values of $x_{s}, w$ is presented both for the condition $\dot{S}=\dot{S}_{\min }$ and the condition $\varepsilon_{\mathrm{Nu}-f}=1$, for the heat exchange of ice slurry during the flow through a tube (Figure 8a) and a slit channel (Figure 8b). The reference values refer to the flow of $10.6 \%$ ethanol and the values of Nusselt numbers and resistance coefficients determined in the same experimental studies as those of ice slurry [12].

The area of values $\left\{x_{s}, w\right\}$ for which $\varepsilon_{\mathrm{Nu}-f}>1$ means that while maintaining the same power associated with the transport of the coolant, the use of ice slurry, compared to using the carrier fluid as the coolant, provides better thermal efficiency

The results presented in Figure 8a show that for the flow through tubes in comparison with the condition $\varepsilon_{\mathrm{Nu}-f}>1$, condition $\dot{S}=\dot{S}_{\min }$ generally shifts the scope of application of ice slurry towards higher flow velocities. The exceptions are low heat flux densities and low tube diameters. For the minimum considered heat flux density of $\dot{q}=2 \mathrm{kWm}^{-2}$ or a small tube diameter of $d_{i}=0.01 \mathrm{~m}$, the minimisation of the entropy flux implies the fulfilment of the condition $\varepsilon_{\mathrm{Nu}-f}>1$. a)
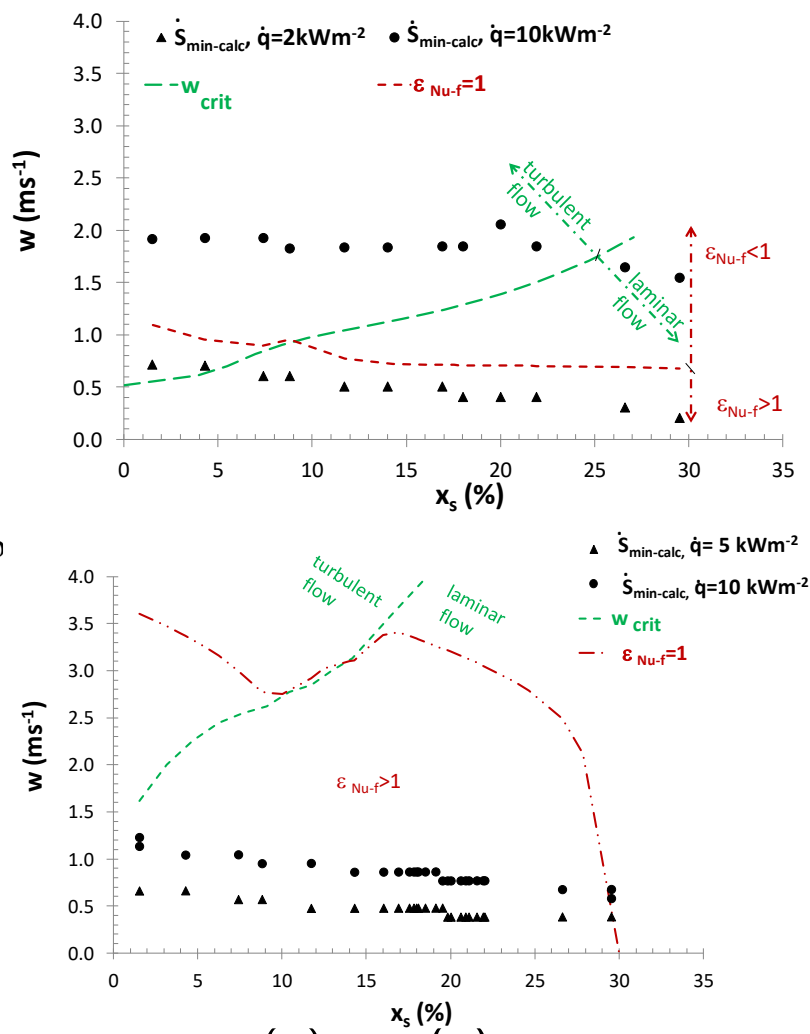

Figure 8. Curves $\mathrm{w}\left(x_{s}\right)_{\dot{S} \min }, w\left(x_{s}\right)_{\varepsilon \mathrm{Nu}-f=1}:$ a) $d_{i}=0.016 \mathrm{~m}$, b) slit channel $a x b=0.003 \times 0.0358 \mathrm{~m}$.

In the case of a slit channel, fulfilment of the criterion $\dot{S}=\dot{S}_{\text {min }}$ ensures that the condition $\varepsilon_{\mathrm{Nu}-f}>1$ is true (Figure $8 b)$. Figure 8 shows that regardless of the criterion adopted for evaluation of the heat exchange process involving ice slurry, the selection of $x_{s}$ and $w$ parameters, the laminar flow area is preferred. In engineering design practice, the 
recommended flow velocities in tubes are $w<1 \mathrm{~ms}^{-1}$. This velocity range for the flow of ice slurry in tubes with a diameter of $d_{i}<0.02 \mathrm{~m}$ enables effective improvement of the heat exchange process with minimal entropy flux values. However, in the laminar flow area, it is advisable to use the maximum possible mass fractions of ice. It should be noted that when designing heat exchangers, in addition to the selection criteria described above for flow velocity and mass fraction of ice, the primary aspect is to ensure the required thermal efficiency. The use of ice slurry melting heat in the heat exchange process minimises the amount of this coolant. In the case of single-phase coolants, higher mass flows are required for receiving identical heat fluxes. Therefore, in the case of high heat flux densities, only the use of a high specific enthalpy agent, i.e. ice slurry, will be preferred.

\section{Conclusions}

The recommended area of flow velocity variability and mass fractions of ice during non-adiabatic flow through tubes and slit channels was presented following entropy flux analysis.

During the flow through tubes, the entropy flux is generally determined by the heat exchange process. This is particularly true for the laminar flow range. In the turbulent flow area and for the flow through a slit channel with entropy flux, flow processes are decisive for the entire flow range.

For the flow through tubes, depending on the mass fraction of ice, optimum slurry velocities can occur in both the laminar and turbulent flow areas. For the flow through the slit channel, optimum flow rates are only found in the laminar flow area.

Optimal flow rates are proportional to the density of the heat fluxes and inversely proportional to the mass fraction of ice. The larger hydraulic diameters of the channel correspond to the higher optimum flow velocities of the ice slurry.

The minimum entropy flux criterion provides an overall enhancement efficiency higher than 1 only in the laminar flow range. The paper proposes a criterion relationship for the flow through tubes and slit channels which allows to determine the flow velocities of ice slurry for which the entropy flux reaches a minimum value for the assumed ice content. The maximum relative error for determining the optimum speed value does not exceed $15 \%$.

\section{Nomenclature}

$$
\begin{aligned}
& \text { A - heat transfer surface, } \mathrm{m}^{2} \\
& \text { Be - Bejan number, - } \\
& c_{f} \quad \text { - Fanning friction factor, - } \\
& C_{i} \quad \text { - coefficients in Eqs. 2.11, } 2.12 \text { (Table 2) } \\
& c_{p} \quad \text { - specific heat, } \mathrm{Jkg}^{-1} \mathrm{~K}^{-1} \\
& \text { d - diameter, } \mathrm{m} \\
& D_{i}, D_{i j^{-}} \text {coefficients in Eqs. 3.2, } 3.3 \text { (Table 3) } \\
& G \quad \text { - mass flux density, } \mathrm{kgm}^{-2} \mathrm{~s}^{-1} \\
& \mathrm{Gz} \quad \text { - Graetz number, } \mathrm{Gz}=\operatorname{Re}_{K} \operatorname{Pr}_{B} \frac{d_{h}}{l} \\
& \text { He - Hedström number, } \mathrm{He}=\frac{\rho_{I S} \tau_{p} d_{h}^{2}}{\mu_{p}^{2}} \\
& i \quad \text { - } \text { specific enthalpy, } \mathrm{Jkg}^{-1} \\
& K^{*} \quad \text { - consistency index } \\
& \mathrm{K}_{\mathrm{F}} \quad-\text { phase change number, } K_{F}=\frac{r}{c_{p-I S}\left(T_{w}-T_{I S}\right)} \\
& l \quad \text { - length, } \mathrm{m}
\end{aligned}
$$$$
\dot{m} \quad \text { - mass flux, } \mathrm{kgs}^{-1}
$$

$n^{*} \quad$ flow behavior index

$\mathrm{Nu}$ - Nusselt number, $\mathrm{Nu}=\frac{\alpha d_{h}}{\lambda}$

$p$ - pressure, $\mathrm{Pa}$

$P \quad$ - circumference, $\mathrm{m}$

$\dot{q}$ - heat flux density, $\mathrm{Wm}^{-2}$

$\dot{Q} \quad$ - heat flux, W

Reв - Reynolds number for Bingham fluid,

$\operatorname{Re}_{B}=\frac{\rho_{I S} w d_{h}}{\mu_{p}}$

$\mathrm{Re}_{\mathrm{K}}$ - generalized Reynolds number according to

Kozicki, $\operatorname{Re}_{K}=\frac{\rho_{I S} w^{2-n^{*}} d_{h}^{n^{*}}}{8^{n^{*}-1} K^{*}}$

$s \quad$ - $\quad$ specific entropy, $\mathrm{Jkg}^{-1} \mathrm{~K}^{-1}$

$\dot{S}_{l} \quad$ entropy generation rate referred to a unit of length,

$\mathrm{WK}^{-1} \mathrm{~m}^{-1}$

$T$ - temperature, $\mathrm{K}$

$T$ - mean temperature, $\mathrm{K}$

$\dot{V} \quad-\quad$ volumetric flow rate, $\mathrm{m}^{3} \mathrm{~s}^{-1}$

$w$ - mean velocity, $\mathrm{ms}^{-1}$

$x_{s} \quad$ - mass fraction of ice, $\%$

$X_{V}$ - volume fraction of ice, $\%$

Greek symbols

$v \quad$ - specific volume, $\mathrm{m}^{3} \mathrm{~kg}^{-1}$

$\alpha \quad-\quad$ heat transfer coefficient, $\mathrm{Wm}^{-2} \mathrm{~K}^{-1}$

$\varepsilon \quad$ - enhancement efficiency

$\varepsilon_{B} \quad-\quad \varepsilon_{B}$ ratio $=\tau_{\mathrm{p}} / \tau_{\mathrm{w}}$

$\lambda$ - thermal conduction coefficient, $\mathrm{Wm}^{-1} \mathrm{~K}^{-1}$

$\mu_{p} \quad$ - dynamic plastic viscosity, $\mathrm{Pa} \mathrm{s}$

$\rho \quad$ - density, $\mathrm{kgm}^{-3}$

$\tau_{p} \quad$ - limit (plastic) shear stress, $\mathrm{Pa}$

$\tau_{w} \quad$ - shear stress at pipe wall, $\mathrm{Pa}$

Subscripts

ai - carrier fluid

calc - calculated value

crit, $C$ critical value

$F \quad$ - fluid

$h$ - hydraulic

$H$ - heat transfer

$i \quad$ - internal, ordinal number

$I S \quad$ - ice slurry

$l$ - length

$L$ - laminar

ref - reference value

$S$ - ice, ice crystal

$T$ - turbulent

$w$ - wall

$\Delta p-\quad$ flow resistance

\section{References}

[1] B. Niezgoda-Żelasko, Modern indirect cooling systems (in Polish). Kraków: Wydawnictwo Politechniki Krakowskiej, 2017.

[2] C. Doetsch, Experimentelle Untersuchung und Modellierung des Rheologischen Verhaltens von IceSlurries (Doctoral dissertation), Universität Dortmund, Germany, 2001.

[3] P.W Egolf, A. Kitanovski, D. Ata-Caesar, E. Stamatiou, M. Kawaji, J.P. Bedecarrats, F. Strub, 
"Thermodynamics and heat transfer of ice slurries", Int. J. Refrig., 28, 51-59, 2005.

[4] B. Niezgoda Żelasko, J. Żelasko, "Melting of ice slurry under forced convection conditions in tubes", Exp. Therm. Fluid Sci., 32, 1597-1608, 2008.

[5] F. Illán', A. Viedma, "Experimental study on pressure drop and heat transfer in pipelines for brine based ice slurry Part II: Dimensional analysis and rheological model", Int. J. Refrig., 32 , 1024-1031, 2009.

[6] S. Mellari, "Experimental investigations of ice slurry flows in horizontal pipe based on monopropylene glycol", Int. J. Refrig, 65, 27-41, 2016.

[7] A.Kitanovski, A.Vuarnoz, D.Ata-Caesar, P.W.Egolf, T.M. Hansen, Ch.Doetsch, "The fluid dynamics of ice slurry", Int. J. Refrig., 28, 37-55, 2005.

[8] B. Niezgoda-Żelasko, J. Żelasko, "Generalized nonNewtonian flow of ice slurry", Chem. Eng. Process., 46, 895-904, 2007.

[9] A.H.P.Skelland, 1967, Non-newtonian flow and heat transfer. New York: John Wiley \& Sons Inc., 1967.

[10] P. Charunkyakorn, S. Sengupta, S.K.Roy, "Forced convective heat transfer in microencapsulated phase change material slurries: flow in circular ducts", Int. J. Heat Mass Trans., 34, 819-833, 1991.

[11] B. Niezgoda Żelasko, J. Żelasko, "Generalized nonnewtonian heat exchange. Flow of ice slurry in pipes", Chem. Process Eng., 30, 453-473, 2009.

[12] B. Niezgoda-Żelasko, Heat transfer and pressure drop of ice slurries flows in tubes (in Polish). Kraków: Wydawnictwo Politechniki Krakowskiej, 2006.

[13] S. Gunes, V. Ozceyhan, O. Buyukalaca, "The experimental investigation of heat transfer and pressure drop in a tube with coiled wire inserts placed separately from tube wall", App. Therm. Eng., 30, 1719-1725, 2010.

[14] A. Bejan, 1996, Method of entropy generation minimization, or modeling and optimization based on combined heat transfer and thermodynamics, Rev. Gén. de Therm., 35, 637-646, 1996.
[15] Y. Demirel, R. Kahraman, "Entropy generation in a rectangular packed duct with wall heat flux", Int. J. Heat Mass Trans., 42, 2337-2344, 1999.

[16] Y. Demirel, R. Kahraman, "Thermodynamic analysis of convective heat transfer in an annular packed bed", Int. J. Heat Fluid Flow, 21, 442-448, 2000.

[17] F. Porras, P. Guevara, G. Soriano, 2013, "A study for entropy generation of heat transfer fluid containing Multiwalled Carbon Nanotubes and Microencapsulated Phase Change Materials" in Innovation in Engineering, Technology and Education for Competitiveness and Prosperity, Proceedings of the 11th Latin American and Caribbean Conference for Engineering and Technology, Cancun, Mexico, pp. 1-11, 2013.

[18] N. Bouzid, S. Saouli, S. Aiboud-Saouli, "Entropy generation in ice slurry pipe flow", Int. J. Refrig., 31, 1453-1457, 2008.

[19] F. Strub, J. Castaing-Lasvignottes, J.P. Bedecarrats, C. Peuvrel, "Application of the second law analysis to a heat exchanger working with ethanol/water ice slurry", Int. J. Therm., 7, 192-188, 2004.

[20] A. Kaymar, S.M. Aminossadati, C.R. Leonardi, "Thermo-hydrodymanics of a helical coil heat exchanger operated with a phase-change ice slurry as a refrigerant", Heat Tran. Eng., 40, 283-294, 2019.

[21] A. Melinder, Thermophysical properties of liquid secondary refrigerants. Tables and diagrams for the refrigerants industry, Paris: IIF/IIR, , 1997.

[22] O. Bel, A. Lallemand, "Etiude d'un fluide frigoporteur diphasique. 2: Analyse expérimentale du comportement thermique et rhéologique", Int. J. Refrig., 22, 175-187, 1999.

[23] A. Melinder, E. Granryd, "Using property values of aquaous solutions and ice to estimate ice concentrations and enthalpies of ice slurries", Int. J. Refrig., 28, 13-19, 2005.

[24] W. Kozicki, C.H.Chou, C. Tiu, "Non-Newtonian flow in ducts of arbitrary cross-sectional shape", Chem. Eng. Sci., 21, 665-679, 1966. 